\author{
Gut Yu. N. ${ }^{1}$, \\ Fedorova T. V.
}

\title{
NEUROPSYCHOLOGICAL APPROACH TO THE DIAGNOSIS AND PREVENTION OF DEVIANT BEHAVIOR
}

1) Candidate of Psychological Sciences, Assistant Belgorod State National Research University,

14-4 Studencheskaya St.,Belgorod, 308007, Russia; E-mail: gut.julya@ yandex.ru

2) EnglishTeacher. Medical College № 9, 5 Savushkina St., Saint Petersburg, 197183, Russia;

E-mail: wildwolf111@yandex.ru

\begin{abstract}
The article is concerned with the main issues of the prevention system of deviant behavior among adolescents in Russia. The necessity of studying the nature of deviant behavior in order to optimize preventive measures is also substantiated. The article gives the description of the results of the study of some neuropsychological pre-requisites found in the functional 10symmetry manifestation, with personality attributes, including the temporal perspective specialities as an indicator of personal maturity / immaturity. It is assumed that the identified interrelations of the functional 10symmetry indicators and the personality attributes of adolescents can be regarded as pre-requisites or deviant behavior, or the personal maturity of adolescents. The data obtained can be used in organizing prevention activities for adolescents while implementing of the principles of differentiated instruction in educational institutions.
\end{abstract}

Keywords : deviant behavior, time perspective, motor screening, personality attributes.

Гут Ю. Н. ${ }^{1}$,

Федорова Т. В. ${ }^{2}$

НЕЙРОПСИХОЛОГИЧЕСКИЙ ПОДХОД К ДИАГНОСТИКЕ И ПРОФИЛАКТИКЕ ДЕВИАНТНОГО ПОВЕДЕНИЯ

1) кандидат психологических наук, ассистент. Белгородский государственный национальный исследовательский университет, ул. Студенческая, 14, к. 4, г. Белгород, 308007, Россия;

E-mail: gut.julya@yandex.ru

2) преподаватель английского языка. Медицинский техникум № 9, ул.Савушкина 5, г. Санкт-Петербург,

197183, Россия; E-mail: wildwolf111@ yandex.ru

The problem of deviant behavior has recently acquired a special significance in Russia. Optimization of the prevention of deviant behavior of young people is one of the priorities of the state youth policy. The relevance of developments in this area is so great that research is conducted in the context of various scientific disciplines such as psychology, sociology, pedagogics, medicine, criminology.

The term "deviation" is derived from Latin and means a deviation from the road [10, p. 73].

The concept of deviant behavior became widespread first in the foreign and then national science.

Despite its being lasting and all-purpose the concept of "deviant behavior" is still not clearly defined. Psychologists focus on specific acts of man and explain this conception as "a system of actions or individual actions, which are contrary to socially accepted legal or moral norms" [9, p. 93]. Sociologists pay great attention to individual behavioral acts and claim that "deviant behavior" is "a person's behavior that violates social laws and the rule of law (criminal and administrative), in contradiction with the rules of the hostel, the organization, customs and traditions" [11, p. 61].

The definitions of the concept of "deviant behavior", proposed by the various branches of social science, complement each other but make the emphasis only on the subject of deviations, which is directly related to their subject of study.

Most researchers agree that deviant behavior is the behavior that diverges from the norms and standards accepted in society and is generally regarded as a negative phenomenon, causing the disapproval of others and exclusion. V.D. Mendelevich believes that this definition requires a 
supplement. First, to determine the deviation it is necessary to know the rules or norms, and secondly, an extraordinary variety of forms of human behavior also includes such a type of behavior as a creative and realising new ideas, which tells of its positive nature. This fact together with the vagueness of the concept of " a norm" complicates the allocation of common criteria for deviant behavior, as well as the development of a uniform classification of behavioral deviancy.

The study of wrongful conduct is recognized as one of the persistent problems of society. The current state of the problem of wrongful conduct is characterized by the absence of a unified theory that would fully disclose the causes and factors that lead to behavioral deviation. There is unanimity of opinion only that deviance is formed and determined by a combination of factors, which include biological conditions, external physical and social conditions, as well as psychological reasons [4].

The principles of the study of deviant behavior are based on the criminological and sociological research. Existing concepts in criminology focus on determining the causes of deviations, investigationg social and personal attributes of the offender; an attempt is made to take into account the impact of society on behavior.

Natural factors play an indirect role in the formation of deviance. They determine the nature of the response of a teenager to the influence of the social environment.

Concepts that define the causes of deviations argue that deviant behavior appears as a result of a complex interaction of social and biological factors that are refracted through the prism of personality [5].

Both social and natural factors determine deviant behavior while integrating into the personal and psychological attributes of deviant adolescents. In human behavior the system of external factors is refracted by the system of internal mechanisms: selfdirection features, time perspective, goal-setting and obtaining aspects, system of values, personal integrity [2, p. 241].

Deviant behavior is a stable socio-negative system of certain ways of a person`s thinking and acting which deviates from the most important law and morality rules, violates personal development and / or is harmful to social environment; a system having signs of social maladjustment, as well as accompanied by negative external attitude and calling for an appropriate reaction on the part of a social group or society as a whole [7].

Thus, having determined the range of the basic concepts describing the exhibitions of deviations in the behavior of adolescents, we will define the prevention of deviant behavior.

S.N. Enikolopov, E.V. Zmanovskaya, M.E. Pozdnyakov and other modern scholars emphasize the effectiveness of preventive activity in comparison with punishment. The most complete definition of the preventing deviant behavior concept was given by $\mathrm{J}$. I. Gilinskii. In his works this concept is defined as the impact of society, social control institutions and individual citizens on the causes of deviant behavior and as the factors that contribute to it, which lead to the reduction or elimination of committing deviant acts [6, p. 70].

Prevention of deviant behavior as a process aimed at eliminating the causes and conditions conducive to behavioral abnormalities of adolescents is an important and necessary aspect of social control of crime. It is well understood that it is not possible to completely prevent the occurrence of offenses, but a partial prediction of those or other forms of criminal activity is possible and necessary [1]. However, in some cases, preventive measures are mostly formal and largerly based on disciplinary measures impact on the students, the dominance of which makes it difficult to raise socially adapted personality in future. Despite being proclaimed at the level of state policy, the development priority of preventive practices at struggle with deviations is far from effective implementation of activities in educational institutions.

Improvement of the effectiveness of management decisions aimed at preventing and overcoming the causes of deviant behavior of adolescents is only possible by the means of coordination of the activity of all the services included in the deviant behavior prevention of minors system and their interdepartmental interaction as well as the interaction with the public and parents. Among the social institutions involved in the prevention, educational institutions must take the lead in this process.

However, in the educational system there are currently some contradictions between the necessity of improving the efficiency of educational and preventive activities and low professional competence of teachers of educational institutions on the issues of the deviant behavior diagnosis and prevention [8]. Taking this into account, the effective organization of educational and preventive work with adolescents, protection of their rights, special training of parents, teachers and educational managers for this kind of activity becomes very urgent.

That is why it is necessary to ensure a coherent and systematic educational process based on up-to- 
date methods and techniques of preventive work in educational institutions.

From our point of view, an important area of prevention of deviant behavior is the development of the practice of diagnosis and prediction of the elaborated cause-factor complex, which causes the development of deviations, and identifying the nature of the interaction of various factors and the implementation of appropriate socio-pedagogical support for children who are prone to deviant behavior.

The success of the prevention activities is certainly dependent on the determination of the preconditions of deviant behavior and its types. At that the social importance of preventive measures will be more effective when having a scientific rationale and taking into account the interaction between social and natural factors that determine the behavior of a person in the already established or perhaps predictable life situations.

The purpose of our study, "Personal and neuropsychological factors of deviant behavior of adolescents" involved identifying the interrelation of types of the functional asymmetry of the brain (determined by the neuropsychological activity of brain structures) and the personality attributes of adolescents, as the prerequisites for deviant behavior [3].

In keeping with this approach, certain empirical research tasks of identifying the prerequisites for deviant behavior or personal immaturity of adolescents were set.

1. To conduct a meaningful analysis of the available science approaches to the study of the role of biological and social factors in the development of deviant behavior.

2. To determine the differential-psychological and neuropsychological components of the similarities and differences among different groups of adolescents - socio-regulatory and anti-social.

3. To compare the types of the functional asymmetry of the brain as a possible natural basis for regulating of behavior of teenagers with a time perspective measures.

4. To identify congruence of certain personality attributes and a time perspective with the type of the functional asymmetry of the brain, which indicate personal maturity or inclination to deviant behavior of adolescents.

5. To determine the ratio of a person`s lateral and individual-psychological specialities associated with a time perspective characteristics, emotional activity in interpersonal interactions, as well as in the behaviour pattern.

The study of the prerequisites of deviant behavior involved 120 adolescents (60 colony inmates , 60 secondary school pupils ) at the age of 15-16 years old.

Three diagnostic unit techniques were used in this study:

1. Techniques "Temporal Orientations" and " The Time Semantic Differential" were used to determine a time perspective as an indicator of personal maturity and psychological characteristics of the individual time perception (E.I. Golovakha, A.A. Kronik).

2. Methods of diagnosing the individual psychological personality traits: R. Cattell's questionnaire (version NSPQ); the method of determining the propensity for deviant behavior (SOP) by A.N. Orel; the technique "The level of neuroticism and psychopathisation" (UNP, The Leningrad Bekhterev Research Institute).

3. Methods of diagnosis of the functional brain asymmetry: motor tests included in the "Map of lateral signs" (A.P. Chuprikov) and used to diagnose the laterality of individuals. As a method of diagnostics of individual differences in the regulatory section of the frontal lobes, A.R.Luria`s motor test " The arms`crossing" ("Napoleon's posture") was used as the only effective measure of latent handedness (N.Sakano). The Japanese scientist N.Sakano proved the validity and reliability of this method in experiments for evoked potentials and research of cognitive processes connected with the functions of the frontal lobes. As known, the frontal lobes are responsible for planning and activitiy control, ie for voluntary functions.

As a result, it was found that the test-persons with the left indicator of the motor test or latent lefthandedness (ie, with manifestations of right-brain functions) are focused mainly in the past, isolated, uncommunicative, able to ignore the generally accepted norms and values and prone to addictive behavior and escape from reality by changing their mental state.

The test-persons with the right indicator of the motor test " The arms'crossing" according to A.R. Luria are oriented in the future, they are more dynamic, adequate and effective in communication situations and tend to demonstrate compliance with the social norms.

The research showed that different propensities for deviant behavior were displayed by the testpersons with the left hand chiasm in conjunction with a set of characteristics of emotional-volitional and communicative spheres such as impulsiveness, irritability, carelessness, emotional instability.

In our opinion, in case of detecting the futurebased time perspective as an indicator of personal maturity, it is possible to prevent the development of tendencies to deviant behavior of adolescents with 
latent left-handedness by creating conditions for the realization of their creative potential resources associated with the dominance of right-brain functions.

The focus on the past implies the existence of a crisis, the causes of which must be found to resolve it; then such adolescents with a tendency to deviation must be directed to creative groups.

The implementation of preventive measures should be started with the expansion of educational resources of school and the capacity of teachers in the field of preventive work on the elimination of the risk of deviant behavior of minors. One of the most important areas of preventive work is training of the diagnosis and assessment specialists: the possibility of deviations in the behavior of students and the development of the preventive and corrective measures. Further, together with specialists from governmental and social institutions these teachers should use the strategy of prevention, taking into account the personality attributes of adolescents.

The proper coordination of subjects of prevention will optimize preventive action. A deeper awareness of the staff of educational institutions and other agencies of the prevention of deviant behavior of minors about juvenile age peculiarities, the types of deviant behavior and its diagnosis and prevention methods will prevent various forms of deviations.

\section{References:}

1. Dictionary of Foreign Words / Under the editorship of F.N. Petrov M .: Russian language, 1999. 624 p.

2. Psychological Dictionary / Under the general editorship of A.V. Petrovsky, M.G. Yaroshevsky. M.: Politizdat, 2001. 494 p.

3. Social pedagogy / Under the editorship of M.A. Galaguzovoy. M., 2000. 440 p.

4. Mendelevich V.D. Psychology of deviant behavior. M.: Publishing house MEDpress, 2001. 432 p.

5. Kudryavtsev, V.V. Fighting motives in criminal behavior. Moscow: Publishing House Norma, 2013. 128 p.

6. Gilinskiy Y.A. Sotsiologiya deviance // Sociological researches. 2009. № 8. PP 70-73.

7. Enikeev M.I. Legal psychology. On the basis of the general and social psychology. M .: Norma, 2005. $641 \mathrm{p}$.

8. Gut Y.N. Personal and neuropsychological prerequisites for deviant behavior of adolescents: Author. Dis. ... Cand. PSC. Sciences. Moscow, 2015. 28 p.

9. Popova E.M., Pedagogical maintenance of prevention of deviant behavior of students of professional educational institutions: Author. Dis. ... Cand. PSC. Science. M., 2011. 24 p.

10. Sakano N. Latent left-handedness. Its relation to hemispheric and psychological functions. Jena: Gustav Fischer Verlag, 1982. 122 p.

11. Boronoev P.G. Comparative-legal analysis of institute of crime prevention in Russia and Japan. UlanUde: Publishing House of the Buryat, Univ:, 2007.

12. Muzaeva J.A. Minimization of problem fields in pedagogical prevention of deviant behavior of orphans in the orphanage: the dissertation ... The candidate of pedagogical sciences: 13.00.01. Omsk, 2007. 207 p. 